\title{
Effect of bronchodilators on the cough response to inhaled citric acid in normal and asthmatic subjects
}

\author{
JC POUNSFORD, MJ BIRCH, KB SAUNDERS \\ From the Department of Medicine I, St George's Hospital Medical School, London
}

ABSTRACT Coughing was induced in seven normal and eight asthmatic subjects by giving successive inhalations of citric acid aerosols of progressively higher concentration (range 0.5-32\%). A baseline cough response was obtained on each of four experimental days, and there was no significant difference between days in this respect. Then the subjects received by inhalation either a bronchodilator (salbutamol $5 \mathrm{mg}$ or ipratropium $1 \mathrm{mg}$ ) or placebo, in a paired double blind crossover design. A second citric acid run followed and was used for paired drug-placebo comparisons. In the asthmatic subjects the cough response was diminished by both bronchodilators ( $p$ $<0.05$ ), and the cough threshold was significantly higher after ipratropium but not salbutamol. In normal subjects no significant effects were found. Airways calibre was assessed, by an oscillatory technique that measures the resistance of the respiratory system (Siemens Siregnost FD 5), in four of the seven normal and all eight asthmatic subjects. The mean respiratory resistance was higher in asthmatic than in normal subjects, and fell significantly after both bronchodilators. In normal subjects smaller decreases in respiratory resistance occurred, significant only with salbutamol. The simplest hypothesis which explains the results relates change in cough response to altered neuroreceptor sensitivity associated with rapid changes in bronchial calibre.

Cough is frequently the only presenting symptom in patients with bronchial asthma. ${ }^{2}$ The cough reflex arises from rapidly adapting receptors located in the larynx, trachea, and major bronchi. ${ }^{34}$ Impulses travel in afferent fibres in the vagus nerve to the cough centre in the brainstem. The tracheobronchial cough receptors are stimulated by touch and inhaled irritants ${ }^{5}$ and sensitised by bronchoconstriction, and this could explain why bronchoconstriction is associated with cough. Cough, in patients with uncomplicated bronchial asthma, is relieved by conventional aerosol bronchodilators. ${ }^{2}$ We have investigated cough induced by inhalation of citric acid in a group of normal and asthmatic subjects, and have assessed the effect of a $\beta_{2}$ stimulant (salbutamol) and an anticholinergic (ipratropium) on the cough response.

\section{Methods}

\section{SUBJECTS}

Eight normal and eight asthmatic subjects were selected. All were non-smokers and had not had a

\footnotetext{
Address for reprint requests: Professor KB Saunders, Department of Medicine I, St George's Hospital Medical School, London SW17 ORE.
}

Accepted 4 April 1985 respiratory infection in the eight weeks preceding the study. One of the normal subjects developed a respiratory infection during the study. Results for the remaining seven are presented. The normal subjects had no history of atopy. The asthmatic subjects had all been inpatients with an acute attack of bronchial asthma during the two years before the study. They were stable and had been out of hospital for at least six months. All were being treated with inhaled salbutamol only, and all gave a history of atopy. Medication was omitted for 12 hours before the experiments.

ASSESSMENT OF COUGH RESPONSE TO INHALED CITRIC ACID

The subjects were asked to breathe through a mouthpiece and a Fleisch pneumotachygraph. Nebulised citric acid solutions were either vented to atmosphere or directed to the mouthpiece via a side tube during a selected inspiration, according to the setting of an electrically operated valve.

To record cough a mercury strain gauge was loosely attached round the subject's neck so that movement of the thyroid cartilage could be detected. The strain gauge was balanced with a Wheatstone bridge circuit and its sensitivity adjusted so that carotid pulsation could be recorded. 
Airway flow, coughing movements, and valve opening were recorded on a Medelec fibreoptic recorder.

Each subject was positioned so that he could see a stop clock marked in seconds and had been trained to inhale from residual volume (RV) to total lung capacity (TLC) in five seconds. After breathing normally for about 20 seconds the subjects exhaled to RV and then inhaled to TLC over a five second period. During this inspiration the valve was opened to deliver the aerosol of citric acid to the subject. After inhalation the subjects exhaled to functional residual capacity and then continued to breathe normally through the mouthpiece for a further 30 seconds, unless coughing occurred.

The citric acid was prepared as solutions at concentrations of $0.5 \%, 1 \%, 2 \%, 4 \%, 8 \%, 16 \%$, and $32 \%$, and delivered as an aerosol from a Wright's nebuliser driven at $101 . \mathrm{min}^{-1}$. Each dose was given as a single inhalation (as described above); the starting concentration was $0.5 \%$, and the dose was increased at four minute intervals to the maximum of $32 \%$.

After each inhalation we counted the number of coughs induced and measured the time between the start of inhalation and the first cough (the latency). We divided the number of coughs by the latency to obtain a further assessment of the cough response, which we called the "cough index." The concentration of citric acid at which coughing first occurred was also recorded-the "cough threshold." A value of $32 \%$ was recorded as the cough threshold if coughing was not induced at all during a run.

ASSESSMENT OF AIR WAY CALIBRE

In the eight asthmatic subjects and four of the seven normal subjects we measured the resistance of the respiratory system (Ros) by an oscillatory technique (Siemens Siregnost SD 5) during normal tidal breathing. Ros varies with tidal breathing, being lowest at end inspiration. We drew a horizontal line of best fit, by eye, through the minimum values of five to eight breaths displayed on a pen recording.

\section{PROTOCOLS}

Each subject attended on four days, at the same time of day. First, a baseline series of citric acid inhalations was given. This was used only to check that baseline conditions were not significantly different in this respect on the four experimental days (see discussion).

Each subject then received inhaled salbutamol ( $5 \mathrm{mg}$ in $3 \mathrm{ml}$ normal saline) paired on another day with placebo ( $3 \mathrm{ml}$ normal saline) or inhaled ipratropium (1 $\mathrm{mg}$ in $3 \mathrm{ml}$ normal saline), again paired on another day with placebo; thus there were four experiments in all. The order of drugs and placebo was randomised in each pair, and the order of the salbutamol pair in respect to the ipratropium pair was also randomised. Neither subject nor investigator knew whether an active preparation or placebo was being given, although a few subjects commented on the taste of ipratropium. For each subject all four experiments were completed within 10 days at the most.

All drug and placebo solutions were nebulised by a raindrop nebuliser (Ideal, Bennett) driven by a Wright's pump at $121 . \mathrm{min}^{-1}$.

Thirty minutes after inhalation of the drug or placebo aerosol the series of citric acid inhalations was repeated. The results from this second series were used to test for differences in cough response between drug and paired placebo days.

Airways calibre was assessed as Ros immediately before and after the baseline series of citric inhalations (that is, once to assess baseline conditions and a second time to assess any effect of citric acid), and a third time just before the second series of citric acid inhalations to test for any drug effect.

\section{STATISTICS}

In assessing changes in standard measurements (for example, Ros) we used the paired $t$ test. When dealing with non-linear or scaled variables (for example, number of coughs, cough index) we used nonparametric methods (Wilcoxon's signed rank test, Friedman's test).

\section{Results}

BASELINE SERIES OF CITRIC ACID INHALATIONS For both normal and asthmatic subjects we summed the total number of coughs and the total of cough indices for each run. There were no significant differences between the four experimental days (Friedman's test; table 1). We repeated the analysis for the number of coughs, looked separately at results for $8 \%, 16 \%$, and $32 \%$ citric acid, and tested for differences between normal and asthmatic subjects. No significant differences were found at any citric acid concentration on any experimental day. Asthmatics did not, in general, cough more than normal subjects in response to citric acid.

The baseline cough threshold did not vary by more than two dosage increments over the four days in any subject.

DRUG EFFECTS ON COUGH RESPONSE

Too few coughs occurred at citric acid concentrations of less than $8 \%$ to allow any statistical analysis. Figure 1 shows the mean number of coughs at $8 \%$, $16 \%$, and $32 \%$ for normal and asthmatic subjects during drug and placebo runs. A possibly significant 
Table 1 Total coughs and cough indices (means with standard errors in parentheses) in all subjects on the four days of the experiment in the baseline citric acid runs

\begin{tabular}{|c|c|c|c|c|c|}
\hline & & Placebo & Salbutamol & Placebo & Ipratropium \\
\hline $\begin{array}{l}\text { Normal subjects }(n=7) \\
\text { Asthmatic subjects }(n=8)\end{array}$ & $\begin{array}{l}\text { Coughs } \\
\text { Cough indices } \\
\text { Coughs } \\
\text { Cough indices }\end{array}$ & $\begin{array}{r}11.60(3.8) \\
5.25(2.6) \\
14.29(3.3) \\
9.69(3.6)\end{array}$ & $\begin{array}{r}10.57(2.6) \\
4.83(2.0) \\
12.30(4.3) \\
11.60(5.3)\end{array}$ & $\begin{array}{c}14.7(7.6) \\
7.9(2.0) \\
11.0(4.2) \\
8.70(4.4)\end{array}$ & $\begin{array}{r}12.90(5.3) \\
5.84(2.3) \\
13.40(4.0) \\
7.91(3.1)\end{array}$ \\
\hline
\end{tabular}

drug effect is seen at all three concentrations in asthmatics, and at $32 \%$ in normal subjects. To test this we used paired results (fig 2) and Wilcoxon's signed rank test. On a few occasions, even at the high citric acid dose concentrations, subjects did not cough either with placebo or with paired active drug. These results are omitted from figure 2 . In normal subjects the coughs induced were not significantly different when placebo and paired active drug were compared (fig 2A). In asthmatic subjects the number of coughs were, with one exception, less after salbutamol or ipratropium (fig $2 \mathrm{~B} ; \mathrm{p}<0.05$ in both cases) at both $16 \%$ and $32 \%$ citric acid doses.

We repeated the analysis using cough index instead of number of coughs, with identical statistical conclusions.
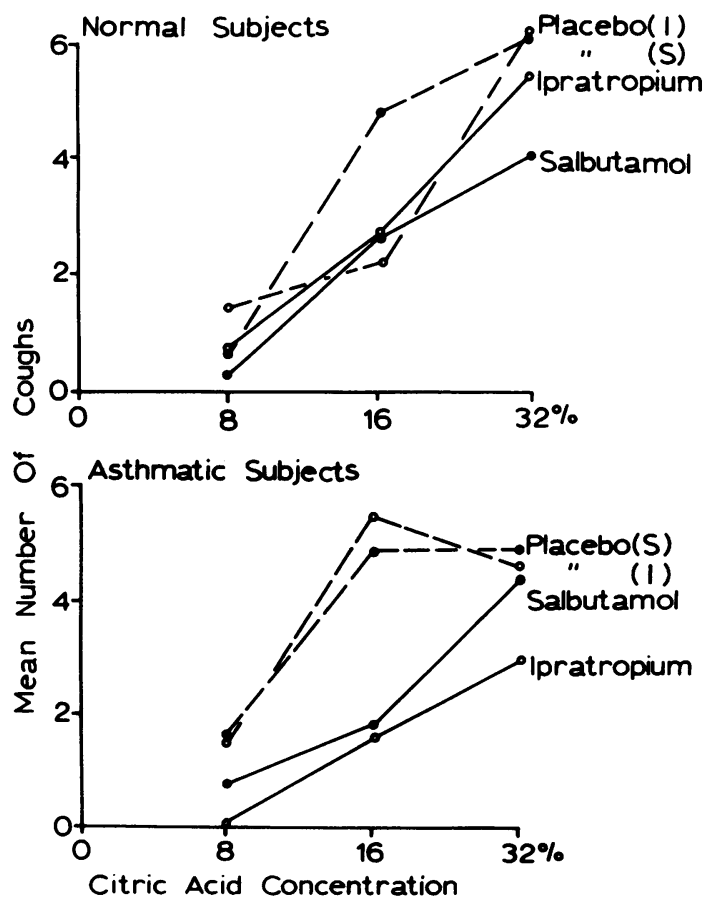

Fig 1 Mean numbers of coughs at the three highest citric acid concentrations in normal and asthmatic groups on the four experimental days. Placebo (I)_paired with ipratropium; placebo (S)_paired with salbutamol.
The cough threshold (fig 3 ) in asthmatic subjects tended to be higher for citric acid runs after active drug than after placebo. This was just significant for ipratropium ( $p<0.05$ ) but not so for salbutamol. There was no significant effect in normal subjects.

Finally, we repeated the analysis, comparing the effect of active drug with the placebo, with which it was not originally paired. For ipratropium there was a significant fall in number of coughs and cough indices with $16 \%$ and $32 \%$ citric acid and a significant rise in threshold, as before $(p<0.05$ in all cases). For salbutamol the cough index fell significantly with $16 \%$ and $32 \%$ citric acid, and the number of coughs with $16 \%$ also fell; but the number of coughs with $32 \%$ citric acid and the cough threshold were unchanged. Again, no significant effects were found in normal subjects.

DRUG EFFECTS ON AIR WAY CALIBRE

Baseline airway calibre was not significantly different on the four experimental days in either normal or asthmatic subjects (table 2). These results in normal subjects refer only to the four who had measurements of Ros. This was not significantly altered after the baseline citric acid run. Ros fell significantly in asthmatic subjects after both salbutamol and ipratropium and in normal subjects after salbutamol.

\section{RELATION BETWEEN CHANGE IN AIRWAY} CALIBRE AND COUGH RESPONSE TO CITRIC ACID In the asthmatic subjects we compared by correlation analysis the change in Ros after active drug or placebo with the total number of coughs induced during the following citric acid run. On eight occasions no coughing was induced, and so $n=(8 \times 4)$ $-8=24$ comparisons. There was a weak but significant correlation $(r=-0.44, p<0.04)$, so that the larger the fall in Ros the smaller was the number of coughs.

\section{Discussion}

Citric acid induces cough in $90 \%$ of human subjects. $^{6}$ The response is rapid and self limiting. The exact mechanism by which cough is stimulated is not known but the high osmolarity' and the acidity of 

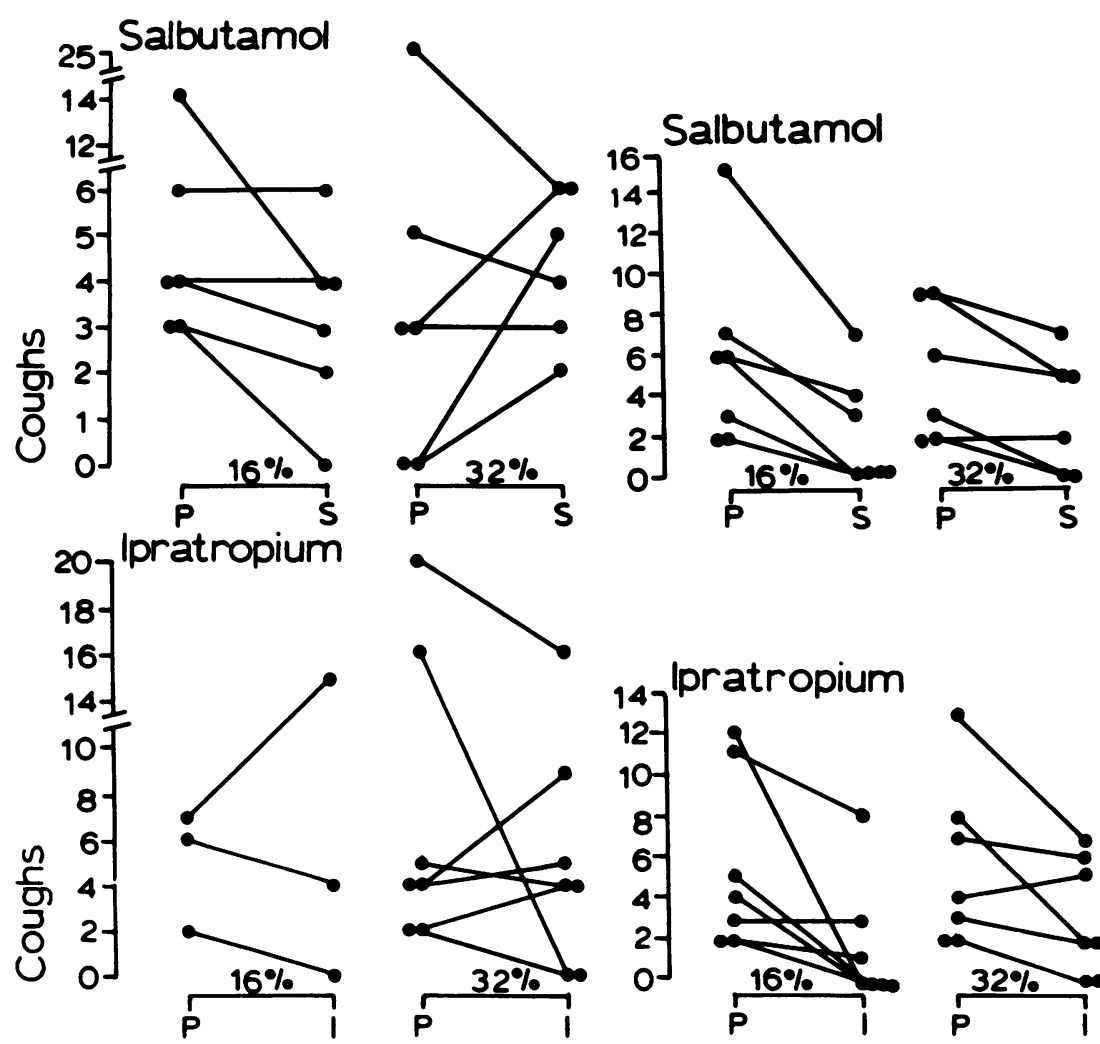

Fig 2 Individual results for number of coughs after active drugs salbutamol (S) and ipratropium (I), paired with placebo $(P)$, at $16 \%$ and $32 \%$ citric acid concentrations.

Normal Subjects A
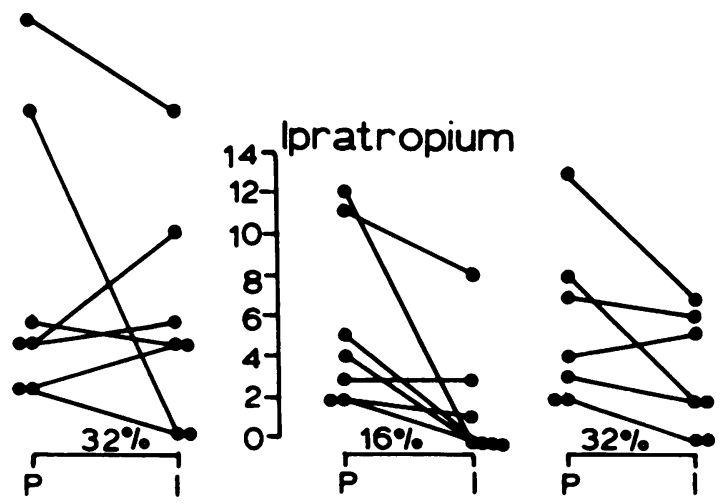

Asthmatic Subjects

B
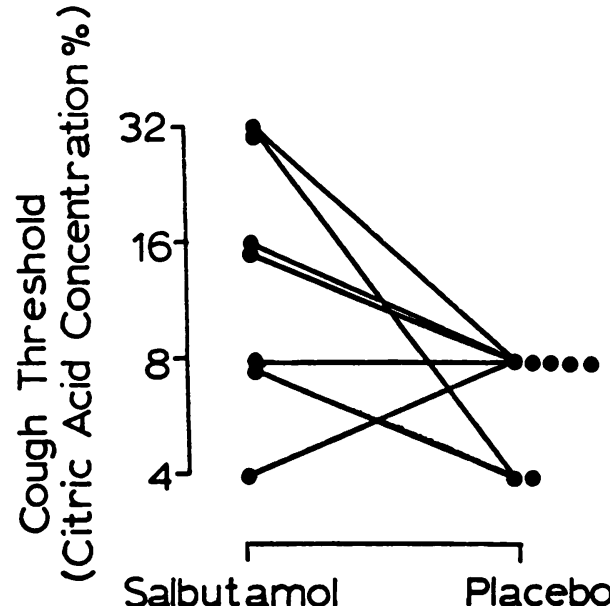

Salbutamol

\section{Placebo}

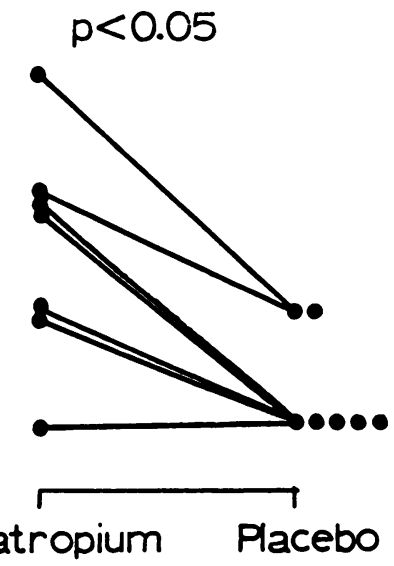

Fig 3 Cough threshold in asthmatic subjects: the results obtained after administration of salbutamol and of ipratropium are connected to those for the results for the paired placebo. 
Table 2 Airways impedance (Ros) (mbar. $1^{-1} . s$, means with standard errors in parentheses) at baseline (B), after baseline citric acid run $(C A)$, and after drug $(A D)$

\begin{tabular}{lllll}
\hline & \multicolumn{2}{l}{ Placebo } & Salbutamol & Ipratropium \\
\cline { 2 - 5 } & Paired with salbutamol & Paired with ipratropium & & \\
\hline Normal subjects $(\mathrm{n}=4)$ & $1.86(0.17)$ & $1.61(0.50)$ & $2.16(0.30)$ & $1.76(0.19)$ \\
B & $1.85(0.12)$ & $2.24(0.38)$ & $1.95(0.22)$ & $1.97(0.29)$ \\
CA & $2.14(0.28)$ & $1.59(0.38)$ & $1.30(0.24) *$ & $1.63(0.14)$ \\
AD & $3.65(0.80)$ & $2.96(0.55)$ & $3.24(0.62)$ & $2.84(0.49)$ \\
Asthmatic subjects $(\mathrm{n}=8)$ & $3.16(0.79)$ & $1.92(0.46)$ & $2.96(0.58) *$ \\
BA & $3.29(0.87)$ & $2.26(0.30)$ & & $1.60(0.24)^{*}$ \\
AD & $2.23(0.36)$ & & & \\
\hline
\end{tabular}

${ }^{*} \mathrm{p}<0.05$ for the comparison between B and AD.

the nebulised solution may be partially responsible. In a study of this kind there are several technical problems which need consideration.

Since there is a diurnal variation in cough response, ${ }^{8}$ tests in an individual subject should be conducted at the same time of day. Since the response adapts over a short time period, ${ }^{8}$ comparisons for drug effect should be made on different days between drug and placebo, not immediately before and soon after drug administration.

Assessment of the magnitude of the response is difficult, since it seems very unlikely that a response of, say, three coughs, represents a receptor response of three times the magnitude of the neural output producing one cough. We have therefore used nonparametric statistics, and our results refer to directional change only-that is, we may say that subjects coughed significantly more, or less; but we cannot say how much more or less. This, however, is sufficient to detect the presence or absence of a drug effect, which is the purpose of this study.

There is considerable variability in the response (fig 2, table 1). We aproached the problem by careful use of separate experiments pairing placebo with each drug, by testing separately for comparability of baseline conditions on each day, and by a double blind design. (Proper double blind trials cannot be done with inhaled ipratropium because of its distinctive taste.) Despite this variability, results for asthmatic subjects were clearcut (fig 2). The possibility of a type 2 statistical error certainly exists so far as negative conclusions are concerned. For example, although we did not show a significant effect in normal subjects, we may have missed one owing to high variability and small numbers.

So far as possible, constant volumes of inhaled citric acid aerosol were given by a standardised inhalation routine. Some subjects coughed before receiving the full dose. We tried to compensate for this by weighting the response according to the shorter latency. ${ }^{8}$ The "cough index" thus obtained gave similar results and identical conclusions.
We assessed airways resistance with a forced oscillation technique. This requires normal breathing through a mouthpiece and a reference impendance of fixed dimensions. An oscillatory flow of air (0.7 $\mathrm{ml}$ at $10 \mathrm{~Hz}$ ) is superimposed on the respired air at the mouthpiece. Measurements of respiratory resistance thus obtained (Ros) correlate well with the results of conventional methods of measuring airways resistance using a body plethysmograph..$^{10}$ Ros varies slightly during the respiratory cycle, and is also affected by involuntary movements of the upper airway structures (for example, glottic closure), and we have therefore used the lower values of Ros recorded during the respiratory cycle, which are less affected by artefact.

Cough arises from stimulation of rapidly adapting airway receptors, which are also stimulated and sensitised by bronchoconstriction. The higher airway tone in asthmatics might imply that the receptors have a higher resting discharge rate than in normal subjects and thus the stimulus required to induce cough would be less. Alternatively, the receptors might be more sensitive to the stimulus of an inhaled irritant. We were surprised that before treatment with bronchodilators there was no clear difference between the sensitivity of normal and asthmatic subjects to citric acid. Recent work does suggest that, in the absence of upper respiratory tract infection, ${ }^{11}$ the cough response is not necessarily related to the degree of bronchoconstriction. ${ }^{7}$ None of our asthmatic subjects had severe airways obstruction, but Ros was higher than in the normal subjects. The cough response appears to be not purely related to the degree of bronchoconstriction, when this is not rapidly changing. This is consistent with the clinical observation that cough in asthmatic patients is not related to the degree of airways obstruction.

Although the initial cough response to citric acid was similar we showed that the normal and asthmatic subjects reacted differently to citric acid after they had received bronchodilators. The bronchodilators had no significant effect in the normal 
subjects but they reduced cough number and cough index in the asthmatic patients, in whom ipratropium also increased the cough threshold.

As ipratropium and salbutamol both diminished the cough response, and both reduce airway tone but by different mechanisms, the relatively rapid change in airway tone is likely to have contributed to our results. The change in Ros was as expected, greater in the asthmatic patients than in the normal subjects. A change in tone could reset irritant receptors and alter the threshold of airways smooth muscle receptors, which are more slowly adapting than irritant receptors. ${ }^{12}$ Discharge from smooth muscle receptors is known to alter with an increase in bronchial tone ${ }^{13}$ and we assume that a reverse effect would also occur.

The simplest explanation for our results is therefore that the cough response depends less on the static level of airways resistance than on sudden changes in its value, and that pulmonary neuroreceptors adapt to any constant level of bronchoconstriction but are then potentiated or inhibited by sudden increases or decreases in airway calibre. In asthmatic subjects a relatively large change in airway calibre after bronchodilators produced a demonstrable effect on cough response. In normal subjects a smaller change in calibre is to be expected (and was found), either too small to change the cough response or producing a change too small to be detected by our methods.

We would like to thank the South West Thames Regional Health Authority, which funded JCP with a locally organised research grant, and BoehringerIngelheim Ltd for additional financial support.

\section{References}

1 Corrao WM, Braman SS, Irwin RS. Chronic cough as the sole presenting manifestation of bronchial asthma. $N$ Engl J Med 1979;300:633-7.

2 Irwin RS, Corrao WM, Pratter MR. Chronic persistent cough in the adult: the spectrum and frequency of causes and successful outcome of specific therapy. Am Rev Respir Dis 1981;123:413-7.

3 Widdicombe JG. Receptors in the trachea and bronchi of the cat. J Physiol 1954;123:71-104.

4 Boushey HA, Richardson PS, Widdicombe JG, Wise JCM. The response of laryngeal afferent fibres to mechanical and chemical stimuli. J Physiol 1974;240: 153-75.

5 Sellick H, Widdicombe JG. Stimulation of lung irritant receptors by cigarette smoke, carbon dust, and histamine aerosol. J Appl Physiol 1971;31:15-9.

6 Bickerman HA, Barach AL. The experimental production of cough in human subjects induced by citric acid aerosol. Am J Med Sci 1954;228:156-63.

7 Eschenbacher WL, Boushey HA, Sheppard D. Alteration in osmolarity of inhaled aerosols causes bronchoconstriction and cough, but absence of a permeant anion causes cough alone. Am Rev Respir Dis 1984;129:211-5.

8 Pounsfound JC, Saunders KB. Diurnal variation and adaptation of the cough response to citric acid. Thorax 1985; 40:657-61.

9 Korn V, Franetzki M, Prestele K. A simplified approach to the measurement of respiratory impedance. In: Progress in respiration research. Vol 11. Basel: Karger, 1979:144-61.

10 Pounsford JC, Davidson RN, Saunders KB. Use of the forced oscillation technique to measure transient changes in airways impedance. Clin Sci 1984;67:7P (abstract).

11 Empey DW, Laitinen LA, Jacobs L, Gold WM, Nadel JA. Mechanisms of bronchial hyperreactivity in normal subjects after upper respiratory tract infection. Am Rev Respir Dis 1976;113:131-9.

12 Widdicombe JG. The site of pulmonary stretch receptors in the cat. J Physiol 1954;125:336-51.

13 Bartlett D, Jeffery P, Sant' Ambrogio G, Wise JCM., Location of stretch receptors in the trachea and bronchi of the dog. J Physiol 1976;258:409-20. 